Jurnal Kepelatihan Olahraga, Universitas Pendidikan Indonesia

\title{
Perbandingan Latihan Menggunakan Pendekatan Teknis dengan Pendekatan Taktis Terhadap Keterampilan Bermain Sepaktakraw
}

\author{
Dina Shintiya ${ }^{1}$, Basiran $^{2}$ \\ ${ }^{1}$ Pendidikan Kepelatihan Olahraga, Fakultas Pendidikan Olahraga dan Kesehatan, Universitas \\ Pendidikan Indonesia, Bandung, Indonesia \\ *dinashintiya05@gmail.com
}

\begin{tabular}{l} 
A B S T R A C T S \\
\hline The purpose of this study is to test which training are more significantly \\
influential between training using a technical approach and training using \\
a tactical approach to the skills of playing Sepaktakraw. The method used \\
is the experimental method which is using the Pretest and Posttest Control \\
Group Design. The population in this study were students who took \\
Sepaktakraw extracurricular activities at SMPN I Citeureup. The \\
sampling technique in this study used a purposive sampling technique, \\
with a sample of 12 people divided into two groups, namely the technical \\
approach group and the tactical approach group. The research instrument \\
used was the Sepaktakraw Play Skill Test Instrument used by M. Husni \\
Thamrin. The data obtained was processed by SPSS version 16 software. \\
This means that there are significant differences between the training \\
using a technical approach and training using a tactical approach to the \\
skills of playing sepaktakraw. Based on these results, it shows that training \\
using a technical approach shows a better improvement compared to \\
training using a tactical approach in improving the skills to play \\
Sepaktakraw. \\
@ 2019 Tim Pengembang Jurnal kepelatihan olahraga \\
A B S T R A K \\
\hline Tujuan penelitian ini untuk menguji latihan manakah yang lebih \\
berpengaruh secara signifikan antara latihan menggunakan pendekatan \\
teknis dengan latihan menggunakan pendekatan taktis terhadap \\
keterampilan bermain sepaktakraw. Metode yang digunakan adalah \\
metode eksperimen dengan menggunakan desain Pretest Posttest Control \\
Group Design. Populasi dalam penelitian ini adalah siswa yang mengikuti \\
ekstrakulikuler sepaktakraw. Teknik pengambilan sampel dalam penelitian \\
ini menggunakan teknik purposive sampling, dengan jumlah sampel 12 \\
orang yang dibagi kedalam dua kelompok yaitu kelompok pendekatan \\
teknis dan kelompok pendekatan taktis. Instrumen Penelitian yang \\
digunakan yaitu Instrumen Tes Keterampilan Bermain Sepaktakraw. \\
Berdasarkan hasil data tersebut menunjukan bahwa latihan menggunakan \\
pendekatan teknis menunjukan peningkatan yang lebih baik bila \\
dibandingkan dengan latihan menggunakan pendekatan taktis dalam \\
meningkatkan keterampilan bermain sepaktakraw. \\
\hline
\end{tabular}

\begin{tabular}{|c|}
\hline ARTICLE INFO \\
\hline $\begin{array}{l}\text { Article History: } \\
\text { Received } 13 \text { Mei } 2019 \\
\text { Revised } 17 \text { June } 2019 \\
\text { Accepted } 29 \text { Agustus } 2019 \\
\text { Available online } 30 \text { Sept } 2019\end{array}$ \\
\hline $\begin{array}{l}\text { Keyword: } \\
\text { Technical Approach, } \\
\text { Tactical Approach, and } \\
\text { Sepaktakraw Play Skills. }\end{array}$ \\
\hline INFO ARTIKEL \\
\hline $\begin{array}{l}\text { Riwayat Artikel: } \\
\text { Diterima } 13 \text { Mei } 2019 \\
\text { Direvisi } 17 \text { Juni } 2019 \\
\text { Diterima } 01 \text { Agustus } 2019 \\
\text { Tersedia online } 30 \text { Sept } 2019\end{array}$ \\
\hline $\begin{array}{l}\text { Kata Kunci: } \\
\text { Pendekatan Teknis, } \\
\text { Pendekatan Taktis, dan } \\
\text { Keterampilan Bermain } \\
\text { Sepaktakraw. }\end{array}$ \\
\hline
\end{tabular}




\section{PENDAHULUAN}

Pembinaan prestasi dalam olahraga, terusmenerus dilakukan baik oleh pemerintah maupun oleh organisasi olahraga. Oleh karena itu, pembinaan setiap cabang olahraga harus diarahkan ke peningkatan prestasi yang nantinya diharapkan akan mengharumkan bangsa. Salah satu nya cabang olahraga sepak takraw.

Menurut sejarah perkembangan nya, sepaktakraw berasal dari olahraga tradisional Indonesia, yaitu Sepak Raga. Daerah-daerah di Indonesia yang semula mengembangkan permainan ini adalah Sumatera Utara, Sumatera Barat dan Sulawesi Selatan. Semula permainan Sepak raga dimainkan oleh sekelompok bangsawan di daerah-daerah tersebut, kemudian berkembang menjadi permainan rakyat. Sepak raga dimainkan 6 sampai 9 orang secara melingkar di suatu tempat terbuka, sebagai hiburan dan pengisi waktu luang dikala orang menunggu waktu senja. Perubahan nama sepak raga jaring menjadi sepaktakraw diresmikan tanggal 27 Maret 1965 di Kuala Lumpur di Stadion negara Kuala Lumpur pada waktu pesta olahraga Asia Tenggara (SEA GAMES). Istilah Sepaktakraw merupakan perpaduan antara bahasa Malaysia dan bahasa Muangthai yaitu sepak berasal dari bahasa Malaysia yang berarti sepak sedangkan takraw berasal dari bahasa Muangthai yang berarti bola rotan.

Sepaktakraw

adalah jenis olahraga campuran dari sepak bola dan bola voli, dimainkan di lapangan ganda bulu tangkis, dan pemain tidak boleh menyentuh bola dengan tangan. Bentuk permainan sepak takraw adalah suatu permainan yang menggunakan bola yang terbuat dari rotan, dimainkan di atas lapangan yang datar berukuran panjang 13,40 m dan lebar 6,10 m. Ditengah-tengah dibatasi oleh jaring net setinggi $1,55 \mathrm{~m}$ seperti permainan bulutangkis. Pemainnya terdiri dari dua pihak yang berhadapan, masing-masing terdiri dari 3 (tiga) orang. Dalam permainan ini yang dipergunakan terutama kaki dan semua anggota badan kecuali tangan. Tujuan dari setiap pihak adalah mengembalikan bola sedemikian rupa sehingga dapat jatuh di lapangan lawan atau menyebabkan lawan membuat pelanggaran atau bermain salah. Sudrajat Prawirasaputra (2000, hlm. 5) menjelaskan bahwa sepaktakraw ialah permainan yang dilakukan oleh dua regu yang berhadapan di lapangan yang dipisahkan oleh jaring (net) yang tebentang membelah lapangan menjadi dua bagian. Setiap regu yang berhadapan terdiri atas tiga orang pemain yang bertugas sebagai tekong yang berdiri paling belakang, dua orang lainnya menjadi pemain depan yang berada disebelah kiri dan kanan yang disebut apit kanan dan apit kiri.

Adapun keterampilan atau teknik dasar yang harus dikuasai oleh para pemain untuk bermain sepak takraw yaitu sepak sila, sepakkuda (sepak kura), menapak, sepak badek, sundulan (heading), mendada, memaha, membahu. Tetapi keterampilan yang paling dominan dalam sepak takraw yaitu sepak sila, sepakkuda, memaha dan heading. Sedangkan teknik khusus dalam permainan sepak takraw adalah sepakmula (servis), blok (menahan), dan 
smash. Seperti yang dijelaskan Prawirasaputra (2000, hlm. 7) bahwa setiap pemain dapat memainkan bola dengan sepakan yang terdiri atas: sepak sila, sepak kuda/ kura, sepak badek atau sepak sepuh (dengan kaki bagian luar), sepak belakang (dengan tumit), sepak cungkit (dengan ujung kaki), menapak (dengan telapak kaki), memaha memainkan bola dengan paha, membahu memainkan bola dengan bahu dan heading memainkan bola dengan sundulan kepala pada dahi, kepala bagian belakang dan samping.

Keberhasilan keterampilan gerak dalam melatih keterampilan bermain sepaktakraw tidak hanya tentukan oleh metode melatih saja, namun banyak faktor internal lain yang berupa kemampuan siswa sendiri. Kemampuan siswa sendiri akan sangat berperan dalam berlatih sepaktakraw. Hal ini dapat dilihat dari gerakan siswa berlatih teknik dasar sepaktakraw, masih banyak siswa yang gerakannya kurang baik atau kurang sempurna sehingga perlu ditingkatan dalam latihan. Adapun tujuan sasaran utama dari latihan adalah untuk membantu atlet meningkatkan keterampilan dan prestasi semaksimal mungkin.

Berdasarkan pengamatan diketahui bahwa keterampilan bermain sepaktakraw siswa yang mengikuti ekstrakulikuler sepaktakraw masih relatif rendah, banyak diantara mereka yang belum mampu melakukan gerakan teknik dasar dan teknik khusus secara baik dan benar. Selain itu, latihan pun masih kurang efektif. Oleh karena itu, perlu kirannya dipilih pendekatan yang sesuai dengan karakteristik siswa dalam taraf latihan keterampilan bemain sepaktakraw.
Penggunan pendekatan latihan yang tepat bagi siswa yang sedang belajar akan memudahkan pelaksanaan proses melatih guna mencapai tujuan yang telah ditetapkan. Adapun, salah satu pendekatan yang dapat digunakan untuk melatih keterampilan bermain sepaktakraw yaitu pendekatan teknis dan taktis. Dari kedua pendekatan tersebut masing-masing memiliki karakteristik yang berbeda dan belum diketahui pendekatan mana yang lebih baik dan efektif untuk meningkatkan keterampilan bermain sepaktakraw pada siswa yang mengikuti ekstrakulikuler sepaktakraw.

Pengertian teknik yaitu cara untuk mencapai tujuan. Maksud kata teknik dalam cabang olahraga adalah gerakan-gerakan yang diperlukan agar mampu melakukan permainan cabang olahraga yang ditekuni oleh atlet. Pendekatan teknis adalah salah satu bentuk pendekatan yang dapat diterapkan pelatih untuk keperluan tertentu misalnya, kebiasaan tertentu, ketangkasan, ketepatan dan lainnya. Pendekatan teknis ini lebih menekankan pada pengulanganpengulangan teknik dasar suatu cabang olahraga. Griffin, Oslin dan Mitchell dalam Yudiana (2010, hlm. 2) menjelaskan bahwa pendekatan teknis yaitu model latihan keterampilan yang lebih menekankan kepada penguasaan keterampilan teknik dasar terlebih dahulu sebelum kepada teknik pola-pola bermain. Sedangkan Sagala (2009, hlm. 21) dalam Eko Supriyanto (2017 hlm. 44) menyatakan bahwa pendekatan teknis adalah pendekatan latihan, atau pendekatan training yang merupakan suatu cara mengajar yang baik untuk menanamkan kebiasaan-kebiasaan tertentu. Juga sebagai 
sarana untuk memperoleh suatu ketangkasan, ketepatan, kesempatan dan keterampilan.

Adapun ciri khas pendekatan ini adalah kegiatan berupa pengulangan yang berkali-kali dari suatu hal yang sama. Seperti dijelaskan oleh Shaleh (2006 : 203) dalam Eko Supriyanto (2017 hlm. 44) bahwa ciri khas dari pendekatan ini (pendekatan teknis) adalah kegiatan yang berupa pengulangan yang berkalikali supaya asosiasi stimulus dan respons menjadi sangat kuat dan tidak mudah untuk dilupakan. Dengan demikian terbentuklah sebuah keterampilan (pengetahuan) yang setiap saat siap untuk dipergunakan oleh yang bersangkutan.

Metode latihan melalui pendekatan teknis sama juga dengan pendekatan tradisional, menurut Griffin, Oslin dan Mitchell dalam Yudiana (2010, hlm. 2) menjelaskan bahwa pendekatan teknis cenderung kepada pendekatan tradisional dalam mengajar/melatih, bahkan tidak meningkatkan kemampuan dalam bermain. Maksudnya pendekatan teknis lebih menekankan kepada peningkatan keterampilan teknik dasar. Seperti yang disampaikan oleh Subroto (2010, hlm. 6) dalam Gian Kharisma (2016, hlm. 22) bahwa Pendekatan tradisional untuk mengajarkan permainan menekankan pada penguasaan keterampilan teknik dasar".

Pendekatan taktis adalah pendekatan yang mengkombinasikan antara latihan keterampilan (skill) dipadukan dengan bentuk permainan. Penggunaan pendekatan taktis dalam melatih keterampilan bermain sepaktakraw, memberikan tugas kepada siswa untuk melakukan latihan keterampilan dalam suasana bermain. Metode latihan pendekatan taktis dirancang dalam suatu proses pembelajaran yang kondusif dapat menghasilkan rasa senang, edukatif, menarik, atau menantang dan dapat menumbuhkan rasa percaya diri. Siswa juga secara otomatis akan mengeluarkan segala kemampuan baik fisik maupun teknik serta dengan cepat harus membuat keputusan dalam situasi permainan.

Bompa 1994 dalam Gian Kharisma (2016, hlm. 15) memperkenalkan pendekatan melatih dan mengajar yaitu pendekatan teknik dan pendekatan taktis permainan. Dan juga diperkenalkan Oslin, Grehaigne, Griffin, dan Mitchell dalam Yudiana (2010) dalam Gian Kharisma (2016 : hlm. 15) mengajar dan melatih pendekatan taktis untuk membantu para pelatih dan guru dalam melatih atau mengajar olahraga permainan.

Melalui latihan yang mirip dengan permainan yang sesungguhnya, minat dan kegembiraan seluruh siswa akan meningkat. Seperti yang dijelaskan Subroto (2016, hlm. 4) dalam Maulana Sidik (2018, hlm. 18) bahwa pendekatan taktis adalah suatu cara untuk meningkatkan kesadaran siswa tentang konsep bermain melalui penerapan teknik yang tepat sesuai dengan masalah/situasi dalam permainan. Beberapa cara mengajar atau melatih teknik sepaktakraw tersebut diantaranya dengan penerapan pola pemahaman permainan (Teaching Game for Understanding). TGFU adalah pola pembelajaran dengan lebih menerapkan pada pemahaman tentang permainan. Pengajaran permainan untuk pemahaman TFGU didasarkan pada enam komponen dasar pembelajaran satu unit permainan, yaitu (Bunker dan Thorpe's, 1986);

(1) Permainan (2) Apresiasi bermain

(3) Kesadaran taktikal (4) Pembuatan keputusan 
yang akurat (5) Eksekusi keterampilan (6) Penampilan.

Tahapan pertama adalah penghantar permainan, termasuk klasifikasinya dan gambaran utuh bagaimana permainan itu dimainkan. Tahapan kedua, melayani dan meyakinkan minat siswa untuk bermain melalui pengajaran sejarah permainannya dan kebiasaankebiasaan yang sering terjdi. Tahapan ketiga, mengembangkan kesadaran taktikal siswa dengan cara menyuguhkan masalah-masalah utama taktis dalam permainan. Tahap keempat, menggunakan aktivias belajar menyerupai permainan untuk membelajarkan siswa mengenali kapan dan bagaimana menerapkan pengetahuan taktikal itu dalam permainan.

Tahapan kelima, memulai kombinasi pengetahuan taktikal dengan pelaksanaan keterampilan dalam aktivitas menyerupai permainan itu. Tahapan keenam, siswa mengembangkan kemampuan penampilan secara benar dan tepat, berdasarkan kombinasi pengetahuan taktkal dan keterampilan.

Ada beberapa pertimbangan yang menguntungkan penggunaan pendekatan

taktis dalam kegiatan latihan keterampilan bermain sepaktakraw. Amung Ma`mun \& Toto Subroto (2001 : 8) dalam Eko Supriyanto (2017 hlm. 54) menyatakan bahwa : "Penggunaan pendekatan taktis memiliki pertimbangan sebagai berikut. 1) Memupuk minat dan kegembiraan, 2) Merangsang untuk berfikir, 3) Pengalihan pemahaman (transfer) melalui bermain (Amung Ma`mun \& Toto Subroto,2001 : 8) Meskipun pendekatan ini mempunyai kelebihan tetapi disisi lain juga terdapat kelemahan yaitu, 1) apabila ada salah satu siswa atau lebih yang kurang menguasai teknik atau keterampilan suatu gerakan akan merugikan siswa lain dalam kelompok tersebut. Sehingga pembelajaran akan sedikit tersendat. 2) Kesalahan teknik yang dilakukan siswa sulit untuk segera diperbaiki karena siswa senang dalam permainan dan terkadang tidak memperhatikan bahwa ia sebenarnya harus memperagakan teknik yang benar".

Penelitian ini bertujuan untuk mengetahui pengaruh dari latihan menggunakan pendekatan teknis terhadap keterampilan bermain sepaktakraw, pengaruh dari latihan menggunakan pendekatan taktis terhadap keterampilan bermain sepaktakraw, serta untuk mengetahui manakah yang lebih signifikan antara latihan menggunakan pendekatan teknis dengan pendekatan taktis terhadap keterampilan bermain sepaktakraw.

\section{METODE}

Metode penelitian yang digunakan dalam penelitian ini adalah metode eksperimen. Desain Penelitian ini menggunakan pre-test and post-test group design, dalam desain ini sampel diperoleh sebesar jumlah populasi, kemudian diadakan tes awal atau pre-test. Test awal dilakukan untuk mengetahui kemampuan awal sampel, dalam hal ini yaitu kemampuan bermain sepaktakraw.

Data hasil tes awal disusun berdasarkan rangking, tujuan nya adalah untuk mengetahui kemampuan keterampilan bermain sepaktakraw sampel mulai dari yang terbesar sampai terendah. Selanjutnya dibagi dua kemudian dua objek yang memiliki skor setaraf dijodohkan menggunakan metode maching sehingga terdapat dua kelompok 
129 | Jurnal Kepelatihan Olahraga, Volume 11 No. 2, September 2019

yang memiliki keterampilan bermain sepak takraw hampir sama.

\subsection{Subjek Penelitian}

Populasi dalam penelitian ini adalah siswa SMP yang mengikuti ekstrakulikuler sepaktakraw yang berjumlah 16 orang. Berdasarkan penjelasan diatas, dengan menggunakan teknik sampel purposive didapatkan sampel sebanyak 12 orang. Adapun karakteristik dari sempel tersebut yaitu siswa kelas 7 dan kelas 8 yang mengikuti ekstrakulikuler sepaktakraw.

\subsection{Prosedur Penelitian}

Prosedur penelitian adalah langkahlangkah yang digunakan sebagai alat untuk mengumpulkan data. Adapun langkahlangkahnya sebagai berikut : (1) menentukan populasi yaitu siswa SMPN yang mengikuti ekstrakulikuler sepaktakraw. (2) menentukan sampel yaitu 12 orang dengan karakteristik hanya siswa kelas 7 dan kelas 8 saja yang mengikuti ekstrakulikuler sepaktakraw. (3) melakukan tes awal kemudian dirangking dari yang tertinggi sampai ke yang terendah dengan teknik A-B-B-A untuk menentukan kelompok teknis dan kelompok taktis. cara ini digunakan agar kedua kelompok mempunyai kemampuan yang seimbang. (4) setelah sudah ditentukan kelompok, selanjutnya diberi treatment latihan menggunakan pendekatan teknis dan pendekatan taktis. (5) kemudian setelah diberi treatment dilakukan tes akhir tes keterampilan bermain sepaktakraw. (6) langkah terakhir yaitu melakukan pengelolahan data, menganalisis dan meranik kesimpulan dari pengelolahan data dan analisis data.
Penelitian ini dilaksanakan selama enam minggu dengan perlakuan eksperimen selama 18 kali pertemuan dengan frekuensi empat kali dalam seminggu yaitu setiap hari Senin, Selasa, Kamis, dan Sabtu.

\section{HASIL PENELITIAN}

Hasil Perhitungan dan Uji signifikasi dapat dilihat pada Tabel 3.1

Tabel 3.1 Paired Sample Test

\begin{tabular}{lccc}
\hline Kelompok & t hitung & t tabel & $\begin{array}{c}\text { Kesimpula } \\
\mathrm{n}\end{array}$ \\
\hline $\begin{array}{l}\text { Tes awal }- \\
\text { Akhir }\end{array}$ & 3,235 & 0,000 & Signifikan \\
Teknis & & & \\
Tes Awal - & 4,297 & 0.000 & Signifikan \\
Akhir & & & \\
Taktis & & & \\
\hline
\end{tabular}

Berdasarkan data diatas penulis menggunakan Uji T Paired pada kelompok A dan Kelompok B untuk mengetahui signifikan atau tidaknya data. Setelah dilakukan uji signifikansi diketahui $\mathrm{T}$ hitung dari kelompok A sebesar 3,235 dengan df 5 pada taraf $\alpha 0,05$ maka $\mathrm{T}$ tabel $=0,000$ maka $\mathrm{T}$ hitung kelompok $\mathrm{A}$ $3,235>0,000$ yang berarti terdapat pengaruh yang signifikan. Sedangkan pada kelompok B T hitung sebesar 4,297 dengan df 5 pada taraf $\alpha$ 0,05 maka $\mathrm{T}$ tabel $=0,000$ maka $\mathrm{T}$ hitung kelompok B 4,297> 0,000 yang berarti terdapat pengaruh yang signifikan pada kelompok B. Lihat Grafik 3.1.

Grafik 3.1. Perbandingan hasil pre-test dan post-test kelompok latihan menggunakan pendekatan teknis 
$\square$ Tes Awal $\quad$ Tes Akhir $\quad$ Gain

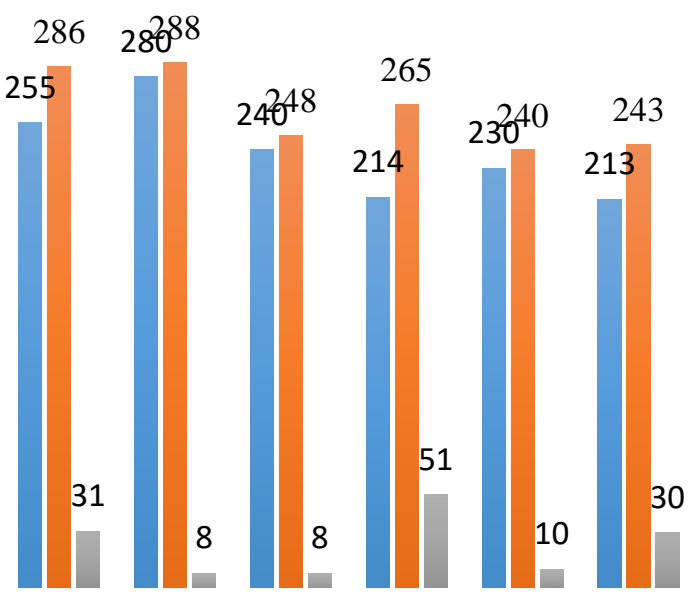

Grafik 3.1 menggambarkan grafik perbedaan hasil latihan pada saat pre-test dan post-test kelompok latihan menggunakan pendekatan teknis. Berdasarkan grafik tersebut disimpulkan bahwa, setelah diberikan treatment latihan menggunakan pendekatan teknis, siswa mengalami peningkatan keterampilan bermain sepaktakraw.

Grafik 3.2. Perbandingan hasil pre-test dan post-test kelompok latihan menggunakan pendekatan taktis

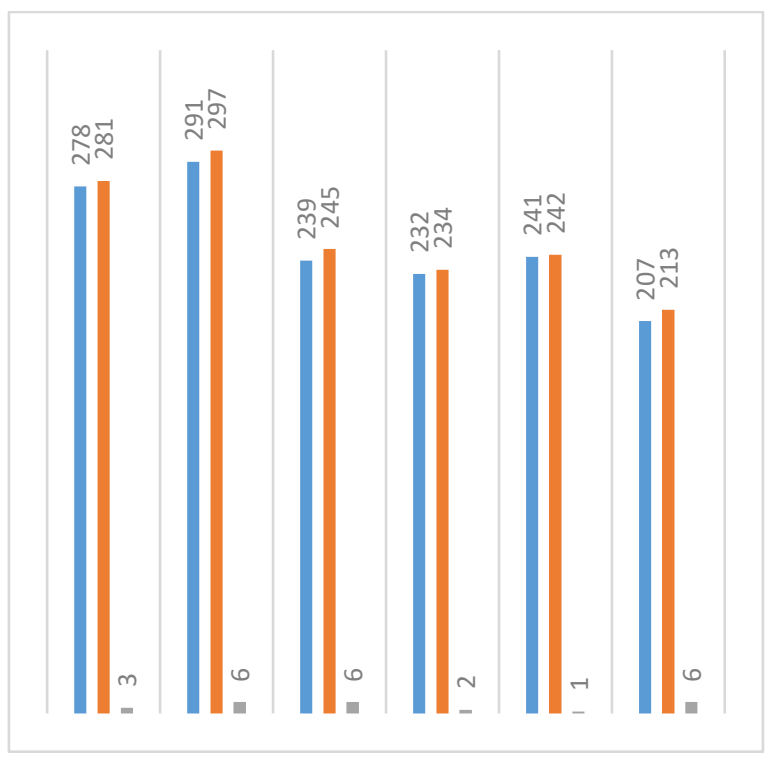

Grafik 3.2. menggambarkan grafik perbedaan hasil latihan pada saat pre-test dan post-test kelompok latihan menggunakan pendekatan taktis. Berdasarkan grafik tersebut disimpulkan bahwa, setelah diberikan treatment latihan menggunakan pendekatan taktis, siswa mengalami peningkatan keterampilan bermain sepaktakraw.

\section{PEMBAHASAN}

Berdasarkan hasil penelitian dan analisis pengolahan data, maka penulis menjelaskan temuan-temuan dari penelitian bahwa latihan menggunakan pendekatan teknis dan pendekatan taktis sama-sama memberikan pengaruh yang signifikan terhadap keterampilan bermain sepaktakraw. Hal ini dapat dilihat dari uji peningkatan dimana kelompok pendekatan teknis mempunyai nilai sebesar $0.008<0.05$, maka Ho ditolak. Yang artinya bahwa terdapat pengaruh yang signifikan dari latihan menggunakan pendekatan teknis. Dan kelompok pendekatan taktis mempunyai nilai $0.024<0.05$, maka Ho ditolak. Yang artinya bahwa terdapat pengaruh yang signifikan dari latihan menggunakan pendekatan taktis.

Kemudian dari hasil tes awal dan tes akhir terdapat perbedaan peningkatan latihan yang signifikan antara pendekatan teknis dengan pedekatan taktis terhadap keterampilan bermain sepaktakraw. Hal ini dapat dilihat dari perbedaan peningkatan antara kelompok latihan menggunakan pendekatan teknis dimana terjadi peningkatan rata-ratanya sebesar 23,00. Sedangkan kelompok latihan dengan menggunakan pendekatan taktis terjadi peningkatan rata-ratanya sebesar 4,00. Dari hasil tersebut dapat disimpulkan bahwa latihan menggunakan pendekatan teknis lebih efektif dibandingkan dengan latihan menggunakan 
pendekatan taktis terhadap keterampilan bermain sepaktakraw.

Selain itu peerbedaan hasil lapangan disebabkan karena keterampilan bermain sepaktakraw dengan menggunakan pendekatan teknis diberikan latihan secara bertahap. Hal ini memberikan kesempatan yang besar bagi atlet untuk menguasai teknik-teknik yang benar dalam melakukan teknik keterampilan bermain dengan baik, maka hasilyang didapat akan baik pula, sehingga atlet dapat menguasai teknik dengan baik dan benar karena dilakukan secara berulangulang setiap latihanPada umumnya pelatih mulai mengajarkan suatu teknik dengan part method. Hal ini disebabkan karena (a) dia menganggap bahwa atlet belum banyak mengenali cara melaksanakan teknik atau keterampilan tersebut, dan (b) pelatih ingin agar atlet melakukan teknik tersebut dengan cara dan metode yang diingini pelatih (Harsono, 1998, hlm. 142).

Dilain pihak, penggunaan pendekatan taktis juga meningkatkan hasil keterampilan bermain sepaktakraw walaupun tidak sebesar pendekatan teknis. Hal ini dikarenakan atlet hanya fokus bermain tanpa mereka sadari bahwa teknik yang mereka lakukan itu benar atau salah dan atlet juga hanya fokus pada keterampilan bermain sepaktakraw yang mendekati kesituasi permainan yang sebenarnya.

Jadi pada penelitian ini pendekatan yang lebih efektif digunakan dalam melatih keterampilan bermain sepaktakraw pada kegiatan ekstrakulikuler adalah pendekatan teknis dalam meningkatkan keterampilan bermain sepaktakraw. Karena dalam ekstrakulikuler kebanyakan siswa belum menguasai cara melakukan gerakan-gerakan teknik dalam bermain sepaktakraw dengan baik. Dengan demikian untuk dapat menguasi teknik keterampilan bermain yang baik diperlukan latihan dengan pendekatan teknis terlebih dahulu.

\section{KESIMPULAN DAN SARAN}

Berdasarkan hasil penelitian yang diperoleh dari analisis pengolahan data, maka kesimpulan dari Perbandingan Latihan Menggunakan Pendekatan Teknis dengan Pendekatan Taktis adalah sebagai berikut : (1) terdapat pengaruh yang signifikan metode latihan menggunakan pendekatan teknis terhadap keterampilan bermain sepaktakraw. (2) terdapat pengaruh yang signifikan metode latihan menggunakan pendekatan taktis terhadap keterampilan bermain sepaktakraw. (3) latihan menggunakan pendekatan teknis memberikan pengaruh yang lebih signifikan dari pada latihan menggunakan pendekatan taktis terhadap keterampilan bermain sepaktakraw.

Atas dasar dari hasil penelitian ini, maka saran yang dapat dikemukakan adalah sebagai berikut : (1) Bagi para pelatih dapat menggunakan pendekatan teknis dan pendekatan taktis untuk melatih keterampilan bermain sepaktakraw. Dari kedua bentuk tersebut, penulis menyarankan bagi para pelatih ketika melatih atlet pemula hendaknya menggunakan pendekatan teknis, karena peningkatannya lebih signifikan dibandingkan pendekatan taktis untuk keterampilan bermain sepaktakraw. (2) Bagi rekan mahasiswa lain yang hendak meneliti kembali tentang perbandingan latihan menggunakan pendekatan teknis dengan latihan menggunakan pendekatan taktis terhadapat keterampilan bermain sepaktakraw, sebaiknya menggunakan populasi sampel yang berbeda dan 
bisa menggunakan instrumen keterampalian Sehingga hasil penelitian akan lebih bermain yang berbeda pula yaitu dengan Games menyempurnakan hasil penelitian ini.

Performance Assesment Instrument (GPAI).

\section{DAFTAR PUSTAKA}

Arikunto, Suharsimi. (2006). Prosedur Penelitian Suatu Pendekatan Praktik. Jakarta: PT. Rineka Cipta.

Darwis, R dan basa, P. (1992). Olahraga Pilihan Sepaktakraw. Padang: Departemen Pendidikan Dan Kebudayaan.

H. M. Husni Thamrin. (2008). Pengembangan Instrumen Tes Ketrampilan Bermain Sepaktakraw Bagi Mahasiswa. Yogyakarta: Lembaga Penelitian UNY.

Hanif, Achmad Sofyan, (2015). Kepelatihan Dasar Sepaktakraw. Semarang : Rajawali Pers.

Harsono. (2015). Kepelatihan Olahraga Teori dan Metodologi. Bandung: PT Remaja Rosdakarya.

Jhon W. Creswell.(2016). Research Design. Edisi dalam Bahasa Indoneisa Pustaka Pelajar.

Kharisma, Gian (2016). Perbandingan Latihan Menggunakan Pendekatan Taktis Dengan Pendekatan Teknis Dalam Meningkatkan Keterampilan Passing Atas Cabang Olahraga Bola Voli .Skripsi Strata 1 Pada FPOK UPI Bandung.

Prawirasaputra, Sudrajat, (2000). Sepaktakraw. Jakarta: Departemen Pendidikan Nasional.

Supriyanto, Eko. (2017). Pengaruh Pendekatan Teknis dan Taktis Terhadap Keterampilan Teknik Dasar Permainan Sepakbola Pada Siswa SMPN 1 Kotabumi. [Online]. Tersedia:https://media.neliti.com/media/publications/193972-ID-pengaruh-pendekatan-teknisdan-taktis-te.pdfgspot.co.id/2017 .

Yudiana, Yunyun. (2010). Implementasi Model Pendekatan Taktik dan Teknik dalam Pembelajaran Permainan Bola Voli pada Pendidikan Jasmani Siswa Sekolah Menengan Pertama. [Online]. Tersedia : http://file.upi.edu/Direktori/FPOK/JUR._PEND._OLAHRAGA/196506141990011. 